\title{
Application of Molecular Diagnostic Techniques for Viral Testing
}

\author{
Fernando Cobo*
}

\author{
Microbiology Unit (Biotechnology Area), Hospital de Poniente. Ctra de Almerimar S/N, El Ejido 04700, Almería, Spain
}

\begin{abstract}
Nucleic acid amplification techniques are commonly used currently to diagnose viral diseases and manage patients with this kind of illnesses. These techniques have had a rapid but unconventional route of development during the last 30 years, with the discovery and introduction of several assays in clinical diagnosis. The increase in the number of commercially available methods has facilitated the use of this technology in the majority of laboratories worldwide. This technology has reduced the use of some other techniques such as viral culture based methods and serological assays in the clinical virology laboratory. Moreover, nucleic acid amplification techniques are now the methods of reference and also the most useful assays for the diagnosis in several diseases. The introduction of these techniques and their automation provides new opportunities for the clinical laboratory to affect patient care. The main objectives in performing nucleic acid tests in this field are to provide timely results useful for high-quality patient care at a reasonable cost, because rapid results are associated with improvements in patients care. The use of amplification techniques such as polymerase chain reaction, real-time polymerase chain reaction or nucleic acid sequence-based amplification for virus detection, genotyping and quantification have some advantages like high sensitivity and reproducibility, as well as a broad dynamic range. This review is an up-to-date of the main nucleic acid techniques and their clinical applications, and special challenges and opportunities that these techniques currently provide for the clinical virology laboratory.
\end{abstract}

Keywords: Automation methods, molecular diagnosis, molecular microbiology, nucleic acid techniques, PCR techniques, viral laboratory diagnosis.

\section{INTRODUCTION}

Molecular diagnostic techniques for viral testing have experimented a rapid development during the last years [1], and have been introduced in the majority of laboratories as a new way for the diagnosis of human pathogens like viruses. This field of molecular microbiology presents many challenges to the practice of laboratory medicine, above all the implementation like automated methodology. The introduction of fully automated devices with faster turnaround times has allowed clinical laboratories the necessary tools to report sensitive and accurate results to physicians. The goals in performing microbiology nucleic acid tests (NAT) are mainly to provide timely results useful for high-quality patient care at a reasonable cost. Rapid results obtained by NAT are associated with improvements in patient care. Empiric data and modeling studies find that faster detection of enteroviral meningitis using NAT is associated with reduced length of stay and duration of antibiotic administration, as well as substantial cost savings [2]. The use of amplification techniques such as polymerase chain reaction (PCR), real-time PCR or nucleic acid sequence-based amplification (NASBA) [3] for virus detection, genotyping and quantification have some advantages like high sensitivity and reproducibility, as well as a broad dynamic range $[4,5]$. A great number of qualitative and quantitative molecular virus assays, mostly

*Address correspondence to this author at the Microbiology Unit (Biotechnology Area), Hospital de Poniente. Ctra de Almerimar S/N, El Ejido 04700, Almería, Spain; Tel: +34950022638;

E-mail: fernando.cobo.sspa@juntadeandalucia.es based on PCR technology have been described $[6,7]$. NASBA assays could identify active infection by detecting viral messenger RNA (mRNA) but the most widely used tests in clinical virus diagnosis are quantitative real-time PCR techniques [8]. Many molecular diagnostic methods have been replaced by automated devices that use less time, manipulate smaller volumes of liquids and provide quantified results with better precision. Molecular techniques have revolutionated the diagnosis of infectious diseases, particularly the diagnosis of viral diseases. Automation of these methods provides decrease in turnaround times, low contamination risk, ease of performance and speed, as well as the ability to have lower detection limits and to diminish cost per test. This review focuses on the application of molecular technology in the clinical virology laboratory.

\section{BRIEF DESCRIPTION OF MOLECULAR TECHNIQUES}

Table 1 summarizes the main molecular techniques used in clinical virology.

\section{NON AMPLIFIED NUCLEIC ACID PROBES}

Nucleic acid probes are segments of DNA or RNA labeled with radioisotopes, enzymes or chemiluminiscent molecules that can bind to complementary nucleic acid sequences of microorganisms. These probes can be used to identify some viruses. The commonly used formats for probe hybridization include liquid-phase, solid-phase and in situ hybridization [9]. In general, these techniques have a poor analytical sensitivity, so they could be used only to those situations in which the number of microorganisms is large. 
Table 1. Summary of Main Molecular Testing Techniques for Viruses

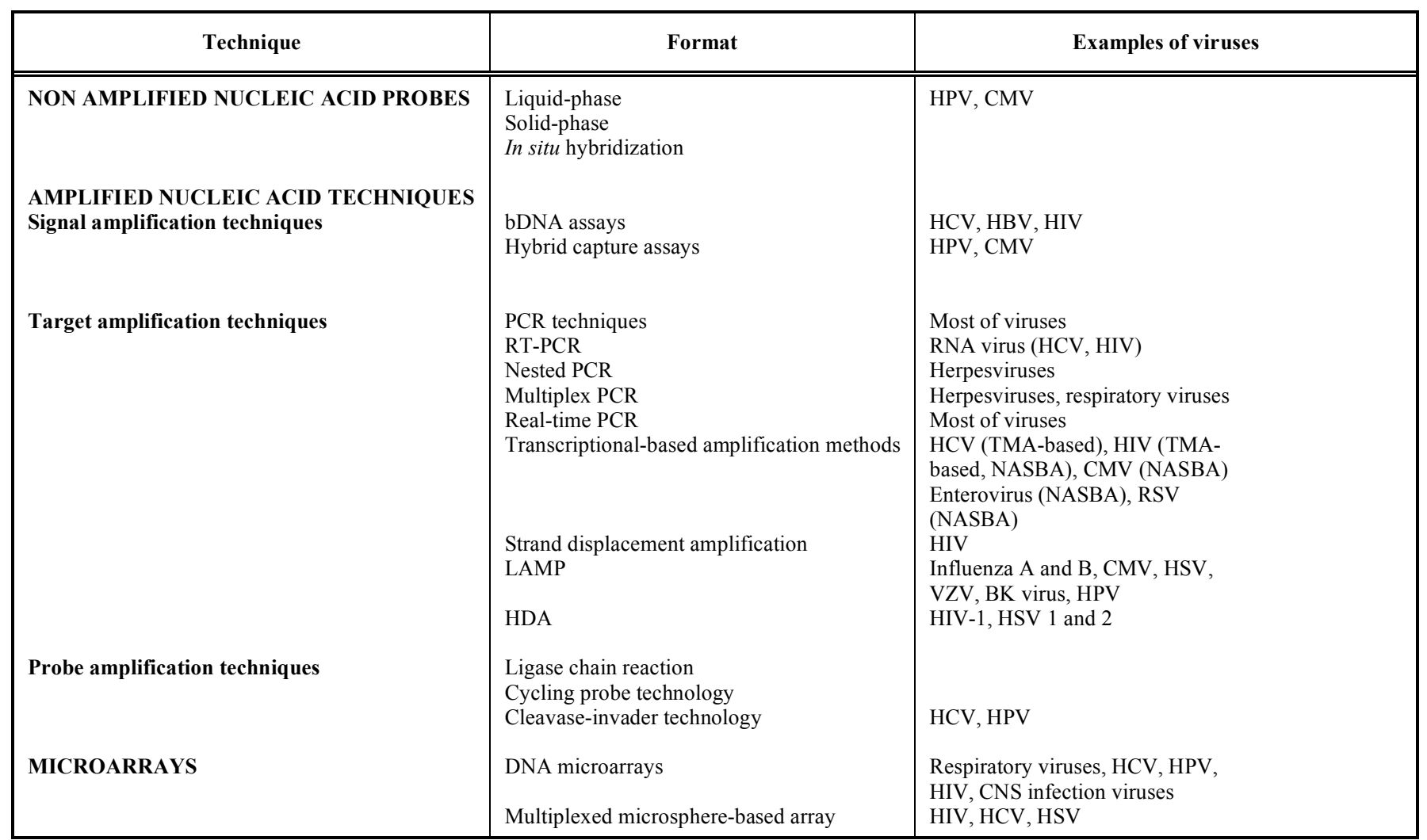

HPV: human papillomavirus; CMV: cytomegalovirus; HCV: hepatitis C virus; HBV: hepatitis B virus; HIV: human immunodeficiency virus; TMA: transcription-mediated amplification; NASBA: nucleic acid sequence-based amplification; RSV: respiratory syncytial virus; DNA: deoxyribonucleic acid; RNA: ribonucleic acid; LAMP: loop-mediated isothermal amplification; HDA: helicase-dependent amplification.

Liquid-phase hybridization assay is a technique in which a single-stranded DNA probe is labeled with an acridinium ester and is then incubated with the target nucleic acid. After hybridization step, the probe binding is measured in a luminometer.

In solid-phase hybridization target nucleic acid bind to nitrocellulose or nylon and is hybridized with a probe solution. The identification is then carried out by means of fluorescence, luminescence, color development or radioactivity. The main limitation of this assay is the time consumption and the complexity of the technique, so application in clinical practice is very limited.

Finally, in situ hybridization is a solid-phase hybridization in which the nucleic acid is contained in cells or tissues fixed in microscope slides. The main disadvantage of in situ hybridization is the limitation of the accessibility of the target nucleic acid in the cells.

\section{AMPLIFIED NUCLEIC ACID TECHNIQUES}

The beginning of molecular diagnostics was initiated at the end of the eighties with the development of the PCR [10]. Although this method is the most widely used nucleic acid amplification technique, other methodologies have been developed. The biochemical mechanisms of these techniques are based on target, signal or probe amplification.

\section{Signal Amplification Techniques}

In signal amplification assays, the signal is directly proportional to the amount of the target sequence present in the clinical specimen, reducing false-positive results due to cross contamination; also, the development of quantitative assays is more reliable.

\section{bDNA Assays}

The branched or bDNA signal amplification system consists of a series of hybridization steps resulting in a "sandwich" complex of probes and target sequence with a branched structure [11]. In this technique, multiple targetspecific probes are used to capture the nucleic acid onto the surface of a microwell plate. The initial step in a bDNA assay is to ensure that viral particles have been disrupted and that viral RNA is present for analysis. Target-specific oligonucleotides are then hybridized to the target nucleic acid, and other regions hybridize to multiple bDNA amplifier molecules that create a branched structure. Finally, the bDNA signal is the chemiluminiscent product of the reaction [11]. The signal in the bDNA assay is proportional to the number of labeled probes bDNA assays for the quantitation of hepatitis $\mathrm{C}$ virus (HCV) RNA, hepatitis $\mathrm{B}$ virus (HBV) DNA and human immunodeficiency virus type 1 (HIV-1) RNA are commercially available (Bayer HealthCare, Diagnostics Division, Tarrytown, N.Y.).

For the detection of $\mathrm{HCV}$, the first-generation bDNA assay (Quantiplex HCV RNA 1.0 assay, Bayer) had a dynamic quantification range in human plasma (from $3.5 \mathrm{x}$ $10^{5}$ to $1.2 \times 10^{8} \mathrm{HCV}$ RNA copies $/ \mathrm{mL}$ ). Genotypes $1-6$ were detected by using this assay, although the sensitivity was lower for genotypes 2 and 3. To improve the detection rate for $\mathrm{HCV}$ genotypes 2 and 3, a second-generation assay was 
developed (Quantiplex HCV RNA 2.0 assay, Bayer). However, a third-generation bDNA assays both for HCV and HIV have been developed (VERSANT HCV RNA 3.0 and VERSANT HIV-1 RNA 3.0 assays, Bayer) that uses isoC and isoG-substituted oligonucleotides to reduce nonspecific hybridization.

\section{Hybrid Capture Assays}

This system is a solution hybridization-antibody capture technique that uses a chemiluminescence detection system of the hybrid molecules. The DNA from the sample is denatured and then hybridized with a specific RNA probe. The DNA-RNA hybrids are captured by anti-hybrids antibodies. The antibody conjugate is detected with a chemiluminescent substrate and a luminometer serves as a device to measure the light emitted. Hybrid capture assays for detection of human papillomavirus (HPV) and cytomegalovirus (CMV) in clinical specimens are currently commercially available (Digene Corp., Gaithersburg, MD) $[12,13]$.

\section{Target Amplification Techniques}

These techniques use enzyme-mediated processes, in which the enzymes synthesize several copies of target nucleic acid. The amplification products are detected by two oligonucleotide primers that bind to complementary sequences. The final result is the production of millions of copies of the targeted sequence. There is possibility of contamination, so false positive results must be reduced through special laboratory design, practices and workflow.

\section{PCR Techniques}

PCR allows the synthesis of million of copies of a targeted nucleic acid sequence. This chemical reaction occurs by means of the action of a DNA polymerase that can copy a DNA strand. PCR consists in a mixture of target DNA, two oligonucleotide primers, a DNA polymerase, a mixture of deoxyribonucleotide triphosphates (dNTPs), $\mathrm{MgCl}_{2}, \mathrm{KCl}$ and Tris- $\mathrm{HCl}$ buffer. The reaction mixture is heated and cooled during several cycles in a programmable thermal cycler, and after $n$ cycles the target sequence can be amplified $2^{\mathrm{n}}$-fold. After the PCR reaction, the detection of product of amplification should be done by means several techniques (e.g. gel analysis, colorimetric detection) [10].

\section{Reverse Transcriptase-PCR}

RT-PCR was introduced to amplify RNA targets. In this method, cDNA is first produced from RNA by reverse transcription and then the cDNA is amplified by PCR. A thermostable DNA polymerase derived from Thermus thermophilus could function efficiently as both an RT and a DNA polymerase [14]. Commercially kits are available for detection of HCV RNA and for quantitation of HIV-1 and HCV RNA in clinical specimens (Roche Diagnostics, Indianapolis, IND).

\section{Nested-PCR}

This modality of PCR increases both the sensitivity and specificity [15]. This technique uses two pairs of amplification primers and two rounds of PCR. In the first round, it uses one primer pair for 15 to 30 cycles. The product of the first round of amplification is submitted to a second round of amplification with the second pair of primers. The major disadvantage of nested PCR is the high rates of contamination.

\section{Multiplex PCR}

In the same reaction mixture, two or more primer sets designed for amplification of different targets are used [16]. More than one target sequence in a clinical specimen can be co-amplified in a single tube. However, the primers used must be carefully selected in order that they have similar annealing temperatures and lack complementarity. This kind of PCR is less sensitive than PCR with single primer set. Multiplex PCR assays for viral respiratory pathogens and for detection of viral infections of central nervous system have been developed and commercialized [17, 18].

\section{Real Time PCR}

In this method, the target amplification and detection steps occur simultaneously. These methods require special thermal cyclers that can monitor the fluorescence emission from the sample. The computer software supporting the thermal cycler monitors the data at every cycle and generates an amplification plot for each reaction [19]. The PCR product is detected by using fluorescent dyes that preferentially bind to double-stranded DNA. The specificity of real-time PCR can also be increased by using fluorescent resonance energy transfer (FRET) probes in the reaction mixture. Another approach to real-time PCR is the use of dual hybridization probes that uses two specially designed sequence-specific oligonucleotide probes. Finally, detection and quantitation of amplification products can be carried out with molecular beacons. Real-time PCR decrease the time required to perform nucleic acid assays because there are no post-PCR processing steps. The main advantages of these methods are also the decrease of contamination and the possibility for quantitative applications.

\section{Transcription-Based Amplification Methods}

There are two methods included in this group: nucleic acid sequence-based amplification (NASBA) and transcription-mediated amplification (TMA). These are isothermal RNA amplification methods modeled after retroviral replication [20, 21]. In both methods, the RNA target is reverse transcribed into cDNA and then RNA copies are synthesized with a RNA polymerase. Transcriptionbased amplification systems have several characteristics such as no requirement for a thermal cycler, rapid kinetics and a single-stranded RNA product that does not require denaturation prior to detection. Gen-Probe has developed TMA-based assays for detection of HCV and HIV-1, while NASBA-based kits (bioMérieux) have developed commercially available kits for the detection and quantitation of HIV-1 RNA and CMV RNA and detection of enterovirus and respiratory syncytial virus RNA.

\section{Strand Displacement Amplification}

This method is an isothermal template amplification technique that can be used to detect trace amounts of DNA or RNA of a particular sequence (Becton Dickinson and Company, Sparks, MD). In its current format, strand displacement amplification occurs in two phases, target generation and exponential target amplification [22]. 
Recently, strand displacement amplification has been adapted to quantitate RNA and RT-Strand displacement amplification has been used for the determination of HIV viral load.

\section{Probe Amplification Techniques}

These methods differ from those that use target amplification in which the amplification products contain only a sequence present in the initial probes. Some examples of probe amplification methods are ligase chain reaction [23], cycling probe technology [24] and cleavase-invader technology [25].

\section{Cleavase-Invader Technology}

Invader assays (Third Wave Technologies, Madison, WS) are based on a probe amplification method with specific recognition of particular DNA structures by cleavase, a member of the FEN-1 family of DNA polymerases. In these assays, two primers are designed which hybridize to the target sequence. Several methods can be used to detect the cleavage products, but Fluorescence Resonance Energy Transfer (FRET) probes and a second invasive cleavage reaction to detect the target-specific products is the most common technique used. FRET occurs due to the interaction between the electronic excited states of two dye molecules. FRET probes are a pair of fluorescent probes placed in close proximity. The excitation is transferred from one dye molecule to the other without emission of a photon. The acceptor fluorophore emits light which is detected in specific channels. This technology is currently available for $\mathrm{HCV}$ genotyping.

\section{Ligase Chain Reaction}

Ligase chain reaction assay is based on the ligation of two adjacent synthetic oligonucleotide primers which hybridize to one strand of the target DNA. A second pair of primers is used in a cycling reaction, using a thermostable DNA ligase. Both ligated products can then serve as templates for the next reaction cycle, leading to an exponential amplification process similar to PCR amplification. Detection of ligase chain reaction product could be carried out by means of several methods such as autoradiography and fluorescence. One of the advantages of the fluorescent detection system is that it is relatively easy to quantitate the amount of the ligase chain reaction product. Other methods for the detection of ligase chain reaction products in microtiter plates are been also used. LCR assays have been developed for the detection of viruses such as $\mathrm{HPV}, \mathrm{HSV}$ and HIV.

\section{Cycling Probe Technology}

Cycling probe technology is a method for detection and quantification of low amounts of target DNA. The reaction is carried out at a temperature that allows the chimeric probe to anneal to the single-stranded target DNA. RNase $\mathrm{H}$, an enzyme that specifically degrades the RNA portion of the DNA-RNA hybrids, cuts within the RNA portion of the chimeric probe, and the shorter probe fragments dissociate from the target, regenerating the target for further cycling. The resulting accumulation of probe fragments can be detected. Since the target DNA is not amplified, this technique shows low background. Moreover, cycling probe technology is fast, linear, isothermal and simple compared with other DNA detection methods.

\section{NEW MOLECULAR TESTS FOR VIROLOGICAL DIAGNOSIS}

\section{Microarrays}

A DNA array (or DNA chip) is a collection of spots attached to a solid support where each spot contains one or more single-stranded DNA oligonucleotide fragment [26]. High density arrays, that permit attaching hundred or thousands of oligonucleotides, are referred to as microarrays. A labeled amplification product is hybridized to the probes, and hybridization signals are mapped to several positions within the array. The pattern of hybridization can identify the sequence of PCR, if the number of probes is sufficiently large. The results of hybridization between the bound probe and labeled sequences in the sample applied and tested are revealed by scanning or imaging the array surface. Confocal microscopy is used to scan the chip, detecting fluorescent signals that reveal hybridization at precise locations on the chip. As many DNA sequences can be present on a slide, it is possible for microarray analysis to test for multiple viruses simultaneously.

The first application in diagnostic virology has been for rapid sequencing to detect HIV mutations associated with resistance to antiretroviral drugs [27]. Since then, some research groups have developed microarrays that detect several viruses such as respiratory viruses [28], hepatitis C virus [29] and virus causing CNS infection [30].

\section{Multiplexed Microsphere-Based Array}

Microsphere-based suspension array technologies, such as the Luminex ${ }^{\circledR} \mathrm{xMAP}^{\mathrm{TM}}$ system, offer a platform for nucleic acid detection that have some advantages including rapid data acquisition, excellent sensitivity and specificity and multiplexed analysis capability [31]. As compared to planar microarrays, suspension arrays have the advantages of ease of use, low cost, statistical superiority, faster hybridization kinetics and more flexibility in array preparation [31].

This system incorporate microspheres dyed with two spectrally different fluorochromes. An array is created consisting of 100 distinct microsphere sets with specific spectrum. A third fluorochrome quantifies the biomolecular interaction that has occurred at the microsphere surface. Microspheres pass through separate lasers in the Luminex analyzer. High speed digital signal processing classifies the microsphere based on its spectral signal and quantifies the reaction on the surface. Thousands of microspheres are analyzed per second resulting in an analysis system capable of analyzing and reporting a lot of different reactions. The assay can be used as direct DNA hybridization, competitive DNA hybridization and solution-based chemistries with microsphere capture.

A multiplexed assay for detection and quantitation of viral nucleic acids using this system has been developed for HIV, HCV and HSV with high specific results [32]. 


\section{ISOTHERMAL METHODS}

Since nucleic acid amplification methods have several disadvantages, such as the requirement for precision thermal cycling, isothermal techniques are being introduced as a diagnostic tool due to their simple operation, rapid reaction and easy detection. These new techniques do not require thermal cycler and can be performed by using a heating block and/or water bath. The main isothermal methods include loop-mediated isothermal amplification (LAMP) and helicase-dependent amplification (HDA) [33].

\section{Loop-Mediated Isothermal Amplification (LAMP)}

This method has improved classical PCR in its reaction simplicity, accuracy and higher amplification efficiency. The procedure is very rapid, and the amplification can be completed in less than 1 hour. The main advantage of LAMP is that it does not require thermal cyclers, and the amplification can be carried out with a water bath or heating block.

LAMP is a one-step amplification reaction that proceeds at isothermal conditions. The chemistry of LAMP amplification is based on the principle of strand displacement reaction, described previously [34]. The mechanism consists in three steps: an initial non-cycling step, a cyclic amplification step and an elongation step. The addition of reverse transcriptase makes it possible to amplify cDNA from RNA (RT-LAMP).

LAMP method has been already used for emerging human viral pathogens such as Dengue and SARS viruses $[35,36]$. Also, RT-LAMP assays have been developed for influenza A and B viruses' detection [37], as well as for CMV, HSV, VZV, BK virus and HPV [38-42].

\section{Helicase-Dependent Amplification (HDA)}

HDA is an isothermal amplification method similar to DNA replication in vivo by using a DNA helicase to separate two complementary DNA strands (dsDNA) and further extension by a DNA polymerase. The initial heat denaturation and subsequent thermocycling are not necessary, and the entire HDA reaction can be performed at a single uniform temperature. This technique provides a useful tool to amplify DNA in vitro under isothermal conditions.

HDA technique has been developed to detect several viruses in different clinical samples such as HIV-1 in human plasma [43] and HSV types 1 and 2 from genital lesions [44].

\section{INTRODUCTION OF MOLECULAR TESTS IN THE CLINICAL VIROLOGY LABORATORY}

Implementation of molecular techniques platforms in the clinical virology laboratory for diagnosis needs some requirements such as personnel and facility requirements and a correct work flow design.

\section{Personnel Requirements}

Laboratory workers must be trained in both the preanalytical (specimen extraction and processing) and the analytical procedures. Professionals that work in this kind of laboratory should have a correct training or experience in molecular methods and also should have theoretical knowledge of molecular virology. The majority of manufacturers provide overview presentations on molecular biology as well as technical information on their specific testing platform. The Director of the Virology Laboratory should provide individualized training in molecular virology for all laboratory workers for success in performing correct molecular testing. It is very important to keep special attention to maintain strict adherence to standard operating procedures (SOP) and avoid the samples contamination using aseptic techniques.

The laboratory must have available detailed SOP, training materials and checklists for each technique performed in the laboratory. Respect to this fact, it would be very important to have a technical expert to provide a reference person in order to apply this methodology in the clinical laboratory. Laboratory-developed tests require that the technical resources to resolve problems related to the assay are available within the laboratory.

\section{Facilities Requirements}

In order to minimize or decrease the risk of specimen contamination, it is necessary a physical separation of processes as well as to have reagents and equipment for use only in the molecular laboratory. Each laboratory should define their work areas but, in general, four different work areas are recommended: a reagent preparation area to prepare PCR master mix, a sample processing area where different procedures are performed (like nucleic acid extraction), a target loading area where the specimen is added to the PCR master mix and an amplification area where thermocycling and probe detection is performed.

The reagent preparation area should be kept free of all specimens and DNA/RNA extracts. The number of tubes that should be simultaneously opened must be minimizing in order to avoid cross-contamination between different samples. An important issue is that the different devices used in PCR such as pipettes, tubes, reagents should be dedicated exclusively to each working area. Reagents should be prepared and aliquoted into single use or small volume.

All working surfaces should be cleaned before and after each use with a reagent that eliminates nucleic acid. The manufacturer's recommendations must be followed for cleaning of instruments, processing blocks and other instrument surfaces and parts.

Gloves should be changed frequently at least before beginning each procedure and must always be changed if moving from one to another work area.

\section{Work Flow Design}

After selection and successful introduction of a molecular testing platform into the virology laboratory, work flow should be implemented at the same time that this technology is being introduced. The main factors to establish an effective work flow are determined by the arrival times of specimens, number of samples of each test, clinical urgency for the results and laboratory functionality. Each laboratory should establish its own work flow depending of each technique and each viral determination, so this fact should be individualized. 
Table 2. Main Viruses, Samples and Molecular Techniques Used for Viral Diagnosis

\begin{tabular}{|c|c|c|c|}
\hline CMV & $\begin{array}{l}\text { CSF } \\
\text { Blood }\end{array}$ & $\begin{array}{l}\text { Conventional qualitative PCR } \\
\text { Real time quantitative PCR } \\
\text { Hybrid capture assay }\end{array}$ & $\begin{array}{l}\text { CNS infection } \\
\text { Congenital infection } \\
\text { CMV immunosuppressed infections }\end{array}$ \\
\hline HSV & $\begin{array}{l}\text { CSF } \\
\text { Blood } \\
\text { Leucocytes } \\
\text { Specimens from genital ulcers or } \\
\text { muco-cutaneous lesions }\end{array}$ & $\begin{array}{l}\text { Nested PCR } \\
\text { Multiplex PCR } \\
\text { Hybrid capture assay } \\
\text { Conventional qualitative PCR } \\
\text { Real time quantitative PCR }\end{array}$ & $\begin{array}{l}\text { Meningo-encephalitis } \\
\text { Neonatal herpes infection } \\
\text { Generalized and visceral herpes infection } \\
\text { in immunosuppressed patients } \\
\text { Dermal and genital diseases }\end{array}$ \\
\hline VZV & $\begin{array}{l}\text { CSF } \\
\text { Exudate from skin lesions } \\
\text { Broncho-alveolar lavage } \\
\text { Amniotic fluid }\end{array}$ & $\begin{array}{l}\text { Real time quantitative PCR } \\
\text { Multiplex PCR }\end{array}$ & $\begin{array}{l}\text { CNS infection } \\
\text { Cutaneous lesions } \\
\text { Pulmonary infections } \\
\text { Congenital and neonatal infections }\end{array}$ \\
\hline Parvovirus B19 & $\begin{array}{l}\text { Blood } \\
\text { Bone marrow } \\
\text { Placental and fetal tissue } \\
\text { Amniotic fluid }\end{array}$ & $\begin{array}{l}\text { Conventional qualitative PCR } \\
\text { Real time quantitative PCR }\end{array}$ & Perinatal and neonatal infections \\
\hline Polyomavirus JC & CSF & $\begin{array}{l}\text { Conventional qualitative PCR } \\
\text { Real time quantitative PCR }\end{array}$ & Leukoencephalopathy \\
\hline Polyomavirus BK & $\begin{array}{l}\text { Urine } \\
\text { Blood samples }\end{array}$ & $\begin{array}{l}\text { Conventional qualitative PCR } \\
\text { Real time quantitative PCR }\end{array}$ & Nephropathy \\
\hline Enterovirus & CSF & $\begin{array}{l}\text { RT-PCR } \\
\text { Real time quantitative PCR }\end{array}$ & CNS infection \\
\hline HPV & $\begin{array}{l}\text { Cervical exudates and biopsies } \\
\text { Warts biopsies } \\
\text { Other biopsies }\end{array}$ & $\begin{array}{l}\text { Type-specific PCR } \\
\text { General primers PCR } \\
\text { Liquid hybridization } \\
\text { HPV mRNA detection } \\
\text { Microarrays }\end{array}$ & $\begin{array}{l}\text { Cervical lesions } \\
\text { Warts }\end{array}$ \\
\hline Hepatitis viruses & $\begin{array}{l}\text { Serum or plasma } \\
\text { Liver tissue }\end{array}$ & $\begin{array}{l}\text { Real time quantitative PCR } \\
\text { Hybridization } \\
\text { Sequencing }\end{array}$ & $\begin{array}{l}\text { Chronic infections (viral load) } \\
\text { Genotyping }\end{array}$ \\
\hline HIV & Plasma & Real time quantitative PCR & Viral load detection \\
\hline
\end{tabular}

CMV: cytomegalovirus; CSF: cerebrospinal fluid; PCR: polymerase chain reaction; CNS: central nervous system; HSV: virus herpes simplex; VZV: virus varicella-zoster; EBV: virus Epstein-Barr; NASBA: nucleic acid sequence-based amplification; HPV: human papillomavirus; HIV: human immunodeficiency virus; RNA: ribonucleic acid.

\section{DESCRIPTION OF MAIN MOLECULAR VIRAL TESTS FOR CLINICAL DIAGNOSIS}

Table 2 shows the main viruses that could be diagnosed by means of molecular techniques as well as the samples and the techniques more appropriate for them.

\section{Cytomegalovirus (CMV) Infection in the Central Nervous System (CNS)}

CMV infection can have several clinical presentations such as non-specific viral syndrome, ocular and congenital disease. Infection can also occur in the CNS, and in the majority of them the clinical presentation is in the form of 
encephalitis, but also as myelitis, radiculomyelopathy and mononeuritis multiplex. Studies suggest that the detection of CMV DNA in the cerebrospinal fluid (CSF) is highly sensitive and specific for CMV neurologic disease [45]. CMV DNA could be detected by conventional PCR in the CSF of HIV patients [46] but is rarely detected in HIVinfected patients without clinical neurological disease. CMV viral load testing using PCR techniques (including real-time PCR) or hybrid capture assays can detect and quantify CMV DNA or DNA-RNA hybrids in clinical specimens, including the CSF [47]. CMV viral load assays can be performed quickly, but it is important to use the same assay while monitoring an individual patient. Interpretation of the results of the viral load is sometimes problematic and unclear because CMV viral load have not been standardized, so it is not possible to define cutoff values.

\section{Herpes Simplex Virus Infections}

Herpes simplex virus (HSV) is a cause of a wide spectrum of clinical manifestations such as CNS, genital and dermal diseases. HSV is the most common cause of nonepidemic sporadic acute focal CNS disease (mainly encephalitis). HSV can also cause aseptic meningitis, usually a self-limited disease that resolves without specific therapy. Because of this, there is a need for a rapid and accurate diagnostic test for HSV CNS diseases, so CSF PCR testing has been evaluated as a diagnostic test for HSV encephalitis and meningitis, being a rapid and a very high sensitivity and specificity diagnostic tool [48]. However, because neither the sensitivity nor specificity is $100 \%$, HSV PCR results should be interpreted with caution. False-negative HSV PCR results could be possible and false-positive HSV PCR results can be also possible due to eventual contamination. Even so, currently it has been established that molecular amplification of HSV DNA is the new gold standard for the laboratory diagnosis of these infections.

PCR is positive early in the course of the illness (within the first 24 hours) and remains positive during the first week of therapy [49]. In some cases, viral genomes persist in the CSF for two weeks or longer after the onset of antiviral therapy [49].

A real-time PCR assay is being used for the diagnosis of CMV, HSV-1 and HSV-2, EBV and VZV from CSF specimens [50]. Compared to conventional PCR, these realtime assays are rapid, simple and convenient for testing for herpesviruses DNA in the routine laboratory. The similarity of clinical features of these viruses is a reason for include several targets for CSF testing rather than for a single unique sequence of one virus.

With respect to dermal and genital disease caused by HSV, real-time HSV PCR assays have emerged as a more sensitive method to confirm HSV infection in clinical specimen obtained from genital ulcers and muco-cutaneous lesions [51]. Conventional PCR was not adapted for the detection of HSV in dermal or genital sources, because cell culture or direct staining techniques were relatively more sensitive for detecting HSV in these specimens. The main limiting factor in introducing real-time HSV PCR as the primary diagnostic tool in the laboratory is the cost of this assay. Moreover, the lack of uniform validation of the PCR assay as a diagnostic method for detecting HSV in clinical specimens other than cerebrospinal fluid has limited its availability in some laboratories.

\section{Varicella-Zoster Virus (VZV) CNS Disease}

VZV is a cause of CNS disease such as encephalitis, myelitis and acute meningitis. In a retrospective study, VZV DNA was detected from 5\% of CSF specimens [47]. Realtime PCR assay provide rapid and sensitive confirmation of VZV from clinical specimens obtained from several samples such as exudate from skin lesions, broncho-alveolar lavage and CSF $[52,53]$. Several studies comparing different assays against real-time PCR have demonstrated that VZV DNA was detected in more samples that the rest of techniques [53, 54]. Moreover, PCR-based testing was highly specific because no cross-reactivity was identified when tested against several other viruses. PCR testing is also useful for other indications such as the diagnosis of VZV infection in a patient with vaccine-modified infection [55], as well as testing of serum or blood might also be helpful in the transplant patient who has visceral disease prior to the appearance of cutaneous lesions [56].

\section{Epstein-Barr Virus (EBV) CNS Lymphoproliferative Disease}

EBV has been implicated in the development of lymphomas, above all in immunosupressed patients. Detection of EBV DNA by molecular techniques in CSF could be useful for the diagnosis of this infection. This technique has a sensitivity of $80-90 \%$ and a specificity that approaches $100 \%$ [57]. Detection of EBV DNA might also be useful in patients in whom a brain biopsy is not possible to do. On the other hand, detection of EBV DNA in CSF also provides a marker to monitor the response to treatment for CNS lymphomas. EBV DNA can be detected by conventional PCR [58], by in situ hybridization [59] and also more recently has been introduced real-time PCR assays to detect EBV DNA from CNS lymphomas [60].

\section{Parvovirus B19}

Infection with parvovirus B19 might cause asymptomatic infection or a wide spectrum of disease (erythema infectiosum in children with arthropathy, severe anemia and systemic affectation) as well as hydrops fetalis, congenital anemia and abortion if the infection is produced in pregnant women.

Although parvovirus B19 infection is diagnosed by serologically detecting $\operatorname{IgM}$ and $\operatorname{IgG}$ class antibodies with ELISA assays, the main application of DNA detection by PCR is the control of transmission of the virus present in blood [61]. Detecting B19 DNA using molecular tests is now being used in many clinical laboratories, and these techniques are much more sensitive than antigen-based detection systems. Most of these techniques detect genotype 1 DNA but not genotypes 2 or 3 .

Some real-time PCR assays such as LightCycler parvovirus B19 quantitative assay (Roche Diagnostics, Indianapolis, IN) and ABI TaqMan (Applied Biosystems) have been developed for detecting B19 nucleic acids in association with infection during pregnancy or assessing the prevalence of the virus DNA in blood products $[62,63]$. The LightCycler parvovirus B19 quantitative assay is highly 
sensitive for genotype 1 but is not suitable for detecting genotypes 2 or 3. With respect to RealArt Parvo B19 LC PCR (Qiagen, Hamburg), this assay can detect all three genotypes according some researchers, but no by others [64]. Appropriate clinical specimens for nucleic acid analysis include plasma, serum, bone marrow, placental and fetal tissues and amniotic fluid.

\section{Polyomaviruses (JC and BK Virus)}

Both viruses were recovered in cell cultures in 1971. BK virus is associated with nephropathy, above all in renal transplant patients as well as in patients with ureteral stenosis and hematuria [65]. On the other hand, it is well knowing the association of JC virus infection with progressive multifocal leukoencephalopathy in immunocompromised patients (such as those with AIDS) [66].

Conventional PCR for detection of JC virus in the cerebrospinal fluid has replaced the brain biopsy for the diagnosis of presence of this virus in patients with leukoencephalopathy [67]. This technique had sensitivity that range $70-90 \%$ and a specificity that range $90-100 \%$ before the highly active antiretroviral therapy [68]. However, at the moment, the application of this therapy recovery the immune system, so the viral replication becomes to be decreased, being JC virus PCR negative in CSF. Currently, it has been developed a qualitative real-time PCR for JC virus detection in CSF.

BK virus can be detected in urine samples by conventional PCR; also, a quantitative real-time PCR technique has been developed to monitoring BK virus DNA in renal transplant recipients [69]. Active BK virus nephropathy is associated with high quantitative levels of BK virus DNA, and resolution of nephropathy was correlated with decreased DNA virus level in urine. However, although it is a sensitive test, the presence of BK virus DNA in this kind of samples does not necessarily means a true infection because there is asymptomatic reactived infection in $10-45 \%$ of renal transplant patients. Therefore, the result should be confirmed using blood samples [70]. In this sense, research has demonstrated that renal transplant recipients with higher urine DNA levels are more likely to show detectable DNA in blood. On the other hand, a negative result does mean no association of BK virus with nephritis.

Finally, PCR from kidney biopsy specimens is not an appropriate test for primary diagnosis of BK nephropathy, because persistent but low-level target DNA in biopsy specimens can be detected in asymptomatic patients [71].

\section{Influenza and Parainfluenza Viruses}

Rapid laboratory diagnosis is critical for infection control, so several diagnostic tests have been developed and are available for the detection of influenza viruses. Rapid influenza diagnostic tests are less sensitive and specific than fluorescent antibody assays and RT-PCR [72]. RT-PCR is the preferred diagnostic assay for influenza virus. These tests are the most sensitive and specific and can differentiate between influenza types (A or B) and subtypes [72]. The main problem of this technique is that it could not be available in all laboratories, so there is a need of other tests in these settings.

Real-time PCR is much more sensitive than other methods of detection and is available for detecting influenza virus [73] but is more expensive.

With respect to parainfluenza viruses, types 1 to 4 have been associated with bronchiolitis, croup and pneumonia in children, but also in elderly and immunocompromised patients. PCR is an adequate technique for the detection of parainfluenza virus, above all in immunocompromised patients [74]. PCR has a sensitivity of $100 \%$ and specificity that range $95-98 \%$ if compared with culture method [75]. Multiplex PCR assays can differentiate between a wide variety of respiratory pathogens [75]. Also, a rapid and sensitive multiplex real-time PCR assay for detection of four serotypes of parainfluenza viruses has been developed [76].

For more information, it can see the article entitled "Laboratory detection of respiratory viruses by automated techniques".

\section{Adenovirus}

PCR is a specific and sensitive assay for detecting adenovirus DNA from a wide variety of clinical specimens, but results must be always interpreted in the context of the clinical findings of adenovirus disease. Quantitative realtime PCR is being now used for the evaluation of adenovirus infections in immunocompromised patients [77]. Moreover, quantification of adenovirus DNA could be useful for assessing response to antiviral therapy [78]. Real-time PCR assays mainly are used to detect adenovirus type 4 (subgroup E) that can cause respiratory, ocular and other infections. The sensitivity of real time PCR against conventional PCR is greater for the detection of adenovirus DNA [79].

\section{Enterovirus CNS Disease}

Enteroviruses such as echoviruses, parechoviruses (echoviruses 22 and 23) and coxsackieviruses A and B could produce several diseases such as respiratory tract infections, aseptic meningitis, myocarditis and neonatal systemic enteroviral disease. Cell culture has a low sensitivity, so molecular techniques like RT-PCR have been developed for the diagnosis of this kind of viruses [80]. Moreover, RTPCR has higher sensitivity than cell culture for detecting enteroviruses in the CSF [81].

A rapid and sensitive detection of enterovirus in CSF could be performed by the introduction of real-time PCR techniques in the laboratory. Real-time PCR assays amplify conserved target nucleic acid sequences of the virus. Sensitivity for detecting enterovirus is similar between conventional PCR and real-time PCR but the last one is less labor intensive and easier to implement in the clinical laboratory [82].

\section{Hepatitis Viruses}

Molecular techniques can be very useful for the diagnosis of viral hepatitis infections such as hepatitis A, B, C, D and $\mathrm{E}$ in cases in which serological assays are no conclusive. However, currently the main application of nucleic acid test in the management of these viruses, above all hepatitis B and $\mathrm{C}$, is the detection of serum or plasma viral load of these 
viruses for monitoring therapeutic responses of infected patients. Assays to quantify hepatitis $\mathrm{B}$ and $\mathrm{C}$ virus load in liver tissue have also been described [83, 84]. HBV DNA detection and HBV DNA viral load are also essential to explore a viral reactivation. Real-time PCR quantification assays are widely used because of their sensitivity, specificity, accuracy, broad dynamic range and positive predictive values. The World Health Organization (WHO) has defined international standards [85]. However, because of these techniques do not use the same HBV primers, follow up of patients should be carried out with the same technical assay in order to compare viral DNA load evolution. With respect to the HBV genotypes, there is currently a need to perform it due to several factors such as the prediction of clinical outcomes and the association with response to interferon treatment [86]. Genotyping of chronic HBV infections can help practicing physicians identify those at risk of disease progression and determine optimal antiviral therapy. Methods to determine the viral genotypes are based on hybridization and sequencing, and genotype affiliation rely on phylogenetic analyses.

With respect to $\mathrm{HCV}$, molecular diagnostic assays represent an essential approach in the management of $\mathrm{HCV}$ patients. Qualitative and quantitative HCV molecular assays are used for the diagnosis of acute and chronic HCV infections, viral genotyping, viral-load determination, treatment, monitoring and prognosis. RT-PCR, transcriptionmediated amplification and branched DNA amplification are commonly employed for detection of HCV RNA. Recently, new HCV molecular assays that employ nanostructures have emerged and have been proposed as suitable, without loss specificity and sensitivity [87].

For more information, it can see the article entitled "Introduction of automated systems for the diagnosis and quantification of Hepatitis B and Hepatitis C viruses".

\section{HIV}

HIV-1 and HIV-2 RNA levels in the plasma of infected patients could be detected by quantitative rapid real-time PCR assays. There are some techniques for this detection that have similar sensitivity and specificity, but differ in the probe and in the amplification-detection systems used.

Quantitative assays for measurement of HIV-1 and HIV2 proviral DNA have also been developed, as well as qualitative real-time PCR assay for detection of proviral DNA.

For more information, it can see the article entitled "Improving clinical laboratory efficiency: introduction of systems for the diagnosis and monitoring of HIV infection".

\section{Human Papillomavirus (HPV)}

Molecular methods to detect HPV DNA in clinical specimens have been introduced in clinical practice, and the majority of protocols for detection of this infection are currently based in the study of HPV DNA. HPV DNA detection could be carried out by several methods such as type-specific PCR, PCR with general primers and liquid hybridization (hybrid capture). Several studies have shown the utility of HPV DNA testing for management of women with abnormal Pap smears [88]. Identifying women at high risk by testing for HPV DNA could avoid unnecessary colposcopy procedures.

For more information, it can see the article entitled "Human papillomavirus (HPV) genotyping: automation and application in routine laboratory testing".

\section{CONCLUSIONS}

The main goal of a clinical virology laboratory is to assist clinicians in the diagnosis and treatment of viral diseases, and to support infection control specialists in their tasks. There is a need for a rapid identification of the etiological microorganisms for an effective patient management.

Since molecular techniques for detecting nucleic acids had been developed, the diagnosis of several viral diseases has been revolutionized in the clinical laboratories. In the majority of them, it has been introduced these methods for routine diagnosis, but some of those are being used only in reference settings.

The main advantages of molecular techniques are its higher sensitivity and specificity compared with other diagnostic methods such as serological assays and culture methods, as well as its rapidity and possibility of automation. From an epidemiological and clinical point of view, these features are very important for the diagnosis of some diseases such as CNS infections, in which the detection of microorganisms should be faster in order to treat rapidly the patients and isolate them to prevent viral transmission of disease. Among this fact, the automation also permits the performance of much more assays and its rapidity helping to improve the patient diagnosis.

Virology laboratories for clinical diagnosis should introduce some of these techniques in order to determine the main viruses implicated in human diseases, after to do an analysis of cost. Laboratory director and technical coordinator should establish the workflow for these techniques enhancing the efficiency of the testing methods. This workflow should be done in an individualized way, taking into account the assays introduced and the special characteristics of the laboratory. Moreover, the personnel should be trained according the best practices for this methodology at this time.

\section{CONFLICT OF INTEREST}

The author declares that they have no competing interests.

\section{ACKNOWLEDGEMENTS}

Declared none.

\section{REFERENCES}

[1] Hayden R, Persing DH. Diagnostic molecular microbiology review. Curr Clin Top Infect Dis 2001; 21: 323-48.

[2] Huizing KMN, Swanink CMA, Landstra AM, van Zwet AA, van Setten PA. Rapid enterovirus molecular testing in cerebrospinal fluid reduces length of hospitalization and duration of antibiotic therapy in children with aseptic meningitis. Pediatr Infect Dis 2011; 30: 1107-9.

[3] Van Belkum A, Niesters HG. Nucleic acid amplification and related techniques in microbiological diagnosis and epidemiology. Cell Mol Biol 1995; 41: 615-23.

[4] Ebner K, Suda M, Watzinger F, Lion T. Molecular detection and quantitative analysis of the entire spectrum of human adenoviruses by a two-reaction real-time PCR assay. J Clin Microbiol 2005; 43: 3049-53. 
[5] Ebner K, Rauch M, Preuner S, Lion T. Typing of human adenoviruses in specimens from immunosupressed patients by PCR-fragment length analysis and real-time quantitative PCR. J Clin Microbiol 2006; 44 : 2808-15.

[6] Ghaffari SH, Obeidi N, Dehghan M, Alimoghaddan K, Gharehbaghian A, Ghavamzadeh A. Monitoring of cytomegalovirus reactivation in bone marrow tranplant recipients by real-time PCR. Pathol Oncol Res 2008; 14: 399-409.

[7] Perandin F, Cariani E, Pollara CP, Manca N. Comparison of commercial and in-house real-time PCR assays for quantification of Epstein-Barr virus (EBV) DNA in plasma. BMC Microbiol 2007; 7: 22.

[8] Atkinson C, Emery VC. Cytomegalovirus quantification: where to next in optimising patient management? J Clin Virol 2011; 51: 223-8.

[9] Arnold LJ Jr., Hammond PW, Wiese WA, Nelson NC. Assay formats involving acridinium ester-labeled DNA probes. Clin Chem 1989; 35: 1588-94.

[10] Saiki RK, Gelfand DH, Stoffel S, et al. Primer-directed enzymatic amplification of DNA with a thermostable DNA polymerase. Science 1988; 239: 487-91.

[11] Nolte FS. Branched DNA signal amplification for direct quantitation of nucleic acid sequences in clinical specimens. Adv Clin Chem 1999; 33: 201-35.

[12] Cope JU, Hildesheim A, Schiffman MH, et al. Comparison of the hybrid capture tube test and PCR for detection of human papillomavirus DNA in cervical specimens. J Clin Microbiol 1997; 35: 2262-5.

[13] Mazzulli T, Drew LW, Yen-Lieberman B, et al. Multicenter comparison of the Digene hybrid capture CMV DNA assay (version $2.0)$, the pp65 antigenemia assay, and cell culture for detection of cytomegalovirus viremia. J Clin Microbiol 1999; 37: 958-63.

[14] Myers TW, Gelfand DH. Reverse transcription and DNA amplification by a Thermus thermophilus DNA polymerase. Biochemistry 1991; 30: 7661-6.

[15] Haqqi TM, Sarkar G, David CS, Sommer SS. Specific amplification with PCR of a refractory segment of genomic DNA. Nucleic Acids Res 1988; 16: 11844.

[16] Chamberlain JS, Gibbs RA, Rainer JE, Nguyen PN, Caskey CT. Deletion screening of the Duchenne muscular dystrophy locus via multiplex DNA amplification. Nucleic Acids Res 1988; 16: 11141-56.

[17] Boriskin YS, Rice PS, Stabler RA, et al. DNA microarrays for virus detection in cases of central nervous system infection. J Clin Microbiol 2004; 42: 5811-8.

[18] Templeton KE, Scheltinga SA, Beersma MF, Kroes AC, Claas EC. Rapid and sensitive method using multiplex real-time PCR for diagnosis of infections by influenza A and influenza B viruses, respiratory syncytial virus, and parainfluenza viruses $1,2,3$ and 4 . J Clin Microbiol 2004; 42: 1564-9.

[19] Higuchi R, Fockler C, Dollinger, Watson R. Kinetic PCR analysis: realtime monitoring of DNA amplification reactions. Biotechnology 1993; 11: $1026-30$.

[20] Compton J. Nucleic acid sequence-based amplification. Nature 1991; 350: 91-2.

[21] Kwoh DY, David GR, Whitfield KM, Chappelle HL, DiMichele LJ, Gingeras TR. Transcription-based amplification system and detection of amplified human immunodeficiency virus type 1 with a bead-based sandwich hybridization format. Proc Natl Acad Sci USA 1989; 86: 1173-7.

[22] Little MC, Andrews J, Moore R, et al. Strand displacement amplification and homogeneous real-time detection incorporated in a second-generation DNA probe system, BDProbe TecET. Clin Chem 1999; 45: 777-84.

[23] Wu DY, Wallace RB. The ligation amplification reaction (LAR) amplification of specific DNA sequences using sequential rounds of template-dependent ligation. Genomics 1989; 4: 560-9.

[24] Suzuki Y, Saito R, Sato I, et al. Identification of oseltamivir resistance among pandemic and seasonal influenza A (H1N1) viruses by a His 275Tyr genotyping assay using the cycling probe method. J Clin Microbiol 2011; 49: 125-30.

[25] Lyamichev V, Mast A, Hall JG, et al. Polymorphism identification and quantitative detection from genomic DNA by invasive cleavage of oligonucleotide probes. Nat Biotechnol 1999; 17: 292-6.

[26] Clinical and Laboratory Standards Institute. Diagnostic nucleic acid microarrays; proposed guideline. CLSI document MMP12-P. Clinical and Laboratory Standards Institute, 2005, Wayne, Pa.
[27] Kozal MJ, Shah N, Shen N, et al. Extensive polymorphisms observed in HIV-1 clade B protease gene using high-density oligonucleotide arrays. Nat Med 1996; 2: 753-9.

[28] Coiras MT, López-Huertas MR, López-Campos G, Aguilar JC, PérezBreña P. Oligonucleotide array for simultaneous detection of respiratory viruses using a reverse-line blot hybridization assay. J Med Virol 2005; 76: 256-64.

[29] Xu X, Li YM, Ji H, Hou CZ, Cheng YB, Ma FP. Changes of ECM and CAM gene expression profile in the cirrhotic liver after HCV infection: analysis by cDNA expression array. World J Gastroenterol 2005; 14 : 2184-7.

[30] Leveque N, Van Haecke A, Renois F, Boutolleau D, Talmud D, Andreoletti L. Rapid virological diagnosis of central nervous system infectionsby use of a multiplex reverse transcription-PCR DNA microarray. J Clin Microbiol 2011; 49: 3874-9.

[31] Dunbar SA. Applications of Luminex ${ }^{\circledR} \mathrm{XMAP}^{\mathrm{TM}}$ technology for rapid, high-throughput multiplexed nucleic acid detection. Clin Chim Acta 2006; 363: 71-82.

[32] Smith PL, WalkerPeach CR, Fulton RJ, DuBois DB. A rapid, sensitive, multiplexed assay for detection of viral nucleic acids using the FlowMetrix system. Clin Chem 1998; 44: 2054-60.

[33] Sidoti F, Bergallo M, Costa C, Cavallo R. Alternative molecular tests for virological diagnosis. Mol Biotechnol 2012; DOI: 10.1007/s12033012-9533-8.

[34] Notomi T, Okayama H, Masubuchi H, et al. Loop-mediated isothermal amplification of DNA. Nucleic Acids Res 2000; 28: E63.

[35] Parida M, Horioke $\mathrm{K}$, Ishida $\mathrm{H}$, et al. Rapid detection and differentiation of dengue virus serotypes by a real-time reverse transcription-loop-mediated isothermal amplificaton assay. J Clin Microbiol 2005 43: 2895-903.

[36] Hong TC, Mai QL, Cuong DV, et al. Development and evaluation of a novel loop mediated isothermal amplification (LAMP) method for rapid detection of SARS Corona virus. J Clin Microbiol 2004; 42: 1956-61.

[37] Ito M, Watanabe M, Nakagawa N, Ihara T, Okuno Y. Rapid detection and typing of influenza $\mathrm{A}$ and $\mathrm{B}$ by loop-mediated isothermal amplification: comparison with immunochromatography and virus isolation. J Virol Methods 2006; 135: 272-5.

[38] Okamoto S, Yoshikawa T, Ihira M, et al. Rapid detection of Varicellazoster virus infection by a loop-mediated isothermal amplification method. J Med Virol 2004; 74: 677-82.

[39] Enomoto Y, Yoshikawa T, Ihira M. Rapid diagnosis of herpes simplex virus infection by a loop-mediated isothermal amplification method. J Clin Microbiol 2005; 43: 951-5.

[40] Suzuki R, Yoshikawa T, Ihira M, et al. Development of the loopmediated isothermal amplification method for rapid detection of cytomegalovirus DNA. J Virol Methods 2006; 132: 216-21.

[41] Bista BR, Ishwad C, Wadowsky R, et al. Development of a loopmediated isothermal amplification assay for rapid detection of $\mathrm{BK}$ virus. J Clin Microbiol 2007; 45: 1581-7.

[42] Hagiwara M, Sasaki H, Matsuo K, Honda M, Kawase M, Nakagawa H. Loop-mediated isothermal amplification method for detection of human papillomavirus type 6, 11, 16 and 18. J Med Virol 2007; 79: 605-15.

[43] Tang W, Chow WHA, Li Y, Kong H, Tang Y, Lemieux B. Nucleic acid assay system for tier II labs and moderately complex clinics to detect HIV in low-resource settings. J Infect Dis 2010; 201: S46-S51.

[44] Kim HJ, Tong Y, Tang W, et al. A rapid and single isothermal nucleic acid amplification test for detection of herpes simplex virus types 1 and 2. J Clin Virol 2011; 50: 26-30.

[45] Flood J, Drew WL, Miner R, et al. Diagnosis of cytomegalovirus (CMV) polyradiculopathy and documentation of in vivo anti-CMV activity in cerebrospinal fluid by using branched DNA signal amplification and antigen assays. J Infect Dis 1997; 176: 348-52.

[46] Minjolle S, Arvieux C, Gautier AL, et al. Detection of herpesvirus genomes by polymerase chain reaction in cerebrospinal fluid and clinical findings. J Clin Virol 2002; 25 (Suppl 1): S59-70.

[47] Aberle SW, Puchhammer-Stöckl E. Diagnosis of herpesvirus infections of the central nervous system. J Clin Virol 2002; 25 (Suppl 1): S79-85.

[48] Lakeman FD, Whitley RJ. Diagnosis of herpes simplex encephalitis: application of polymerase chain reaction to cerebrospinal fluid from brain-biopsied patients and correlation with disease. J Infect Dis 1995; 171: $857-63$.

[49] Wildemann B, Ehrhart K, Storch-Hagenlocher B, et al. Quantitation of herpes simplex virus type 1 DNA in cells of cerebrospinal fluid of patients with herpes simplex virus encephalitis. Neurology 1997; 48: 1341-46. 
[50] Stöcher M, Holzl G, Stekel H, Berg J. Automated detection of five human herpes virus DNAs by a set of Light Cycler PCRs complemented with a single multiple internal control. J Clin Virol 2004; 29: 171-8.

[51] Smith TF, Uhl JR, Espy MJ, et al. Development, implementation, and trend analysis of real-time PCR tests for the clinical microbiology laboratory. Clin Microbiol Newsl 2004; 26: 145-54.

[52] Stránská R, Schuurman R, de Vos M, van Loon AM. Routine use of a highly automated and internally controlled real-time PCR assay for the diagnosis of herpes simplex and varicella-zoster virus infections. J Clin Virol 2004; 30: 39-44.

[53] Schmutzhard J, Merete Riedel H, Zweygberg WB, Grillner L. Detection of herpes simplex virus type 1 , herpes simplex virus type 2 and varicella-zoster virus in skin lesions. Comparison of real-time PCR, nested PCR and virus isolation. J Clin Virol 2004; 29: 120-6.

[54] Harbecke R, Oxman MN, Arnold BA, et al. A real-time PCR assay to identify and discriminate among wild-type and vaccine strains of varicella-zoster virus and herpes simplex virus in clinical specimens, and comparison with the clinical diagnoses. J Med Virol 2009; 81: 1310-22.

[55] Leung J, Harpaz R, Baughman AL, et al. Evaluation of laboratory methods for diagnosis of varicella. Clin Infect Dis 2010; 51:23-32.

[56] de Jong MD, Weel JF, van Oers MH, Boom R, Wertheim-van Dillen PM. Molecular diagnosis of visceral herpes zoster. Lancet 2001; 357: 2101-2.

[57] Yarchoan R, Jaffe ES, Little R. Diagnosing central nervous system lymphoma in the setting of AIDS: a step forward. J Natl Cancer Inst 1998; 90: 346-7.

[58] Broccolo F, Iuliano R, Careddu AM, et al. Detection of lymphotropic herpesvirus DNA by polymerase chain reaction in cerebrospinal fluid of AIDS patients with neurological disease. Acta Virol 2000; 44: 137-43.

[59] Phan TG, O'Neill BP, Kurtin PJ. Posttransplant primary CNS lymphoma. Neurooncology 2000; 2: 229-38.

[60] Bossolasco S, Cinque P, Ponzoni M, et al. Epstein-Barr virus DNA load in cerebrospinal fluid and plasma of patients with AIDS-related lymphoma. J Neurovirol 2002; 8: 432-8.

[61] Weimer T, Streichert S, Watson C, Gröner A. High-titer screening PCR: a successful strategy for reducing the parvovirus B19 load in plasma pools for fractionation. Transfusion 2001; 41: 1500-4.

[62] Harder TC, Hufnagel M, Zhan K, et al. New LightCycler PCR for rapid and sensitive quantification of parvovirus B19 DNA guides therapeutic decision-making in relapsing infections. J Clin Microbiol 2001; 39: 4413-9.

[63] Knöll A, Louwen F, Kochanowski B, Plentz et al. Parvovirus B19 infection in pregnancy: quantitative viral DNA analysis using a kinetic fluorescence detection system (TaqMan PCR). J Med Virol 2002; 67: 259-66.

[64] Hokynar K, Norja P, Laitinen H, Palomäki et al. Detection and diferentiation of human parvovirus variants by commercial quantitative real-time PCR tests. J Clin Microbiol 2004; 42: 2013-9.

[65] Li RM, Mannon RB, Kleiner D, et al. BK virus and SV40 co-infection in polyomavirus nephropathy. Transplantation 2002; 74: 1497-1504.

[66] Du Pasquier RA, Kuroda MJ, Zheng Y, Jean-Jacques J, Letvin NL, Koralnik IJ. A prospective study demonstrates an association between $\mathrm{JC}$ virus specific cytotoxic $\mathrm{T}$ lymphocytes and the early control of progressive multifocal leukoencephalopathy. Brain 2004; 127: 1970-78.

[67] Telenti A, Aksamit AJ, Proper J Jr, Smith TF. Detection of JC virus DNA by polymerase chain reaction in patients with progressive multifocal leukoencephalopathy. J Infect Dis 1990; 162: 858-61.

[68] Cinque P, Scarpellini P, Vago L, Linde A, Lazzarin A. Diagnosis of central nervous system complications in HIV-infected patients: cerebrospinal fluid analysis by the polymerase chain reaction. AIDS 1997; 11:1-17.

[69] Randhawa P, Ho A, Shapiro R, et al. Correlates of quantitative measurement of BK polyomavirus (BKV) DNA with clinical course of
BKV infection in renal transplant patients. J Clin Microbiol 2004; 42: 1176-80.

[70] Randhawa P, Vats A, Shapiro R. Monitoring for polyomavirus BK and $\mathrm{JC}$ in urine: comparison of quantitative polymerase chain reaction with urine cytology. Transplantation 2005; 79: 984-6.

[71] Schmid H, Nitschko H, Gerth J, et al. Polyomavirus DNA and RNA detection in renal allograft biopsies: results from a European multicenter study. Transplantation 2005; 80: 600-4.

[72] Ginocchio CC, Zhang F, Manji R, et al. Evaluation of multiple test methods for the detection of the novel 2009 influenza A (H1N1) during the New York City outbreak. J Clin Virol 2009; 45: 191-5.

[73] Boivin G, Côté S, Déry P, De Serres G, Bergeron MG. Multiplex realtime PCR assay for detection of influenza and human respiratory syncytial viruses. J Clin Microbiol 2004; 42: 45-51.

[74] Mahony JB. Detection of respiratory viruses by molecular methods. Clin Microbiol Rev 2008; 21: 716-47.

[75] Liolios L, Jenney A, Spelman D, Kotsimbos T, Catton M, Wesselingh S. Comparison of a multiplex reverse transcription-PCR-enzyme hybridization assay with conventional viral culture and immunofluorescence techniques for the detection of seven viral respiratory pathogens. J Clin Microbiol 2001; 39: 2779-83.

[76] Templeton KE, Scheltinga SA, Beersma MF, Kroes AC, Claas EC. Rapid and sensitive method using multiplex real-time PCR for diagnosis of infections by influenza A and influenza B viruses, respiratory syncytial virus, and parainfluenza viruses $1,2,3$ and 4 . J Clin Microbiol 2004; 42: 1564-69.

[77] Claas EC, Schilham MW, de Brouwer CS, et al. Internally controlled real-time PCR monitoring of adenovirus DNA load in serum or plasma of transplant recipients. J Clin Microbiol 2005; 43: 1738-44.

[78] Lankester AC, van Tol MJ, Claas EC, Vossen JM, Kroes AC Quantification of adenovirus DNA in plasma for management of infection in stem cell graft recipients. Clin Infect Dis 2002; 34: 864-7.

[79] Heim A, Ebnet C, Harste G, Pring-Akerblom P. Rapid and quantitative detection of human adenovirus DNA by real-time PCR. J Med Virol 2003; 70: 228-39

[80] Rotbart HA, Robero JR. Laboratory diagnosis of enteroviral infections. In: Rotbart HA, Ed. Human enterovirus infections. Washington DC: ASM Press, 1995; pp. 401-18.

[81] Pozo F, Casas I, Tenorio A, Trallero G, Echevarria JM. Evaluation of a commercially available reverse transcription-PCR assay for diagnosis of enteroviral infection in archival and prospectively collected cerebrospinal fluid specimens. J Clin Microbiol 1998; 36: 1741-5.

[82] Rabenau HF, Clarici AM, Muhlbauer G, et al. Rapid detection of enterovirus infection by automated RNA extraction and real-time fluorescence PCR. J Clin Virol 2002; 25: 155-64.

[83] White PA, Pan Y, Freeman AJ, Ffrench RA, Lloyd AR, Rawlinson WD. Quantification of hepatitis $\mathrm{C}$ virus in human liver and serum samples by using LightCycler reverse transcriptase PCR. J Clin Microbiol 2002; 40: 4346-8.

[84] Zanella I, Rossini A, Domenighini D, Albertini A, Cariani E. Real-time quantitation of hepatitis B virus (HBV) DNA in tumorous and surrounding tissue from patients with hepatocellular carcinoma. J Med Virol 2002; 68: 494-9.

[85] Saldanha J, Gerlich W, Lelie N, Dawson P, Heermann K, Heath A. An international collaborative study to establish a World Health Organization international standard for hepatitis B virus DNA nucleic acid amplification techniques. Vox Sang 2001; 80: 63-71.

[86] Lin CL, Kao JH. The clinical implications of hepatitis B virus genotype: recent advances. J Gastroenterol Hepatol 2011; 26 (Suppl 1): 123-30.

[87] Al Olaby RR, Azzazy HM. Hepatitis C virus RNA assays: current and emerging technologies and their clinical applications. Expert Rev Mol Diagn 2011; 11: 53-64.

[88] Manos MM, Kinney WK, Hurley IB, et al. Identifying women with cervical neoplasia: Using human papillomavirus DNA testing for equivocal Papanicolaou results. JAMA 1999; 281: 1605-10. 